\title{
Talking Different Languages of Value
}

\subsection{Returning to the Culture- WELL-BEING RELATIONSHIP}

The arguments of cultural value are curious, yet mundane. Chapters 6 and 7 offered glimpses of how some people argue about the value of culture one way, while others seem to speak a different language entirely. The language of data, metrics and numeric valuations of culture can feel at odds with how the majority of artists and cultural practitioners speak and think about culture. In one hand, we might hold a 2010 report of the UK's Department for Culture, Media and Sport (DCMS) (O'Brien 2010), which offers an overview of evaluation techniques, such as Quality Adjusted Life Years (or QALYs ${ }^{1}$ ). While, in the other, we might hold a copy of the Arts Council England (ACE) Strategy from the same year, ${ }^{2}$ in which artist Jeremy Deller explains that art makes 'life worth living' (ACE $2010,26)$. The report in one hand talks cost-benefit analysis, while in the other, artist Tim Etchells speaks of artistic 'value not bound up with price' (ACE 2010, 26).

Many in the cultural sector ${ }^{3}$ are sceptical that cultural experience can be expressed in quantitative terms (Hill 2017; Oman 2013; Oman and Taylor 2018), with some being adamant that it should not be (Nissel 1983; Meyrick and Barnett 2021). Academic research on cultural metrics is equally two-sided (Belfiore 2002; Merli 2002; Selwood 2002; Gilmore et al. 2017). The gentler end of the critical scale involves damning metrics

(C) The Author(s) 2021

S. Oman, Understanding Well-being Data, New Directions in Cultural Policy Research, https://doi.org/10.1007/978-3-030-72937-0_8 
with faint praise by stating that '[s]tatistical data well channelled can provide useful ancillary information' (Phiddian et al. 2017, 179); the harsher end involves describing 'ideas pertaining to the measurement of culture's value' as 'stupid' (Meyrick and Barnett 2017, 109).

The previous chapter outlined some differences in quantitative expressions of the culture-well-being relationship. It began with a walk through some examples of how data could be and are used to understand questions about culture and well-being. This step-by-step approach aims to open 'the black box' of well-being data (and some culture data for good measure). It is not always easy for everyone to have a practical sense of how data are used, or how they work, with the way that arguments and workings are generally shared. Looking closely at how analysis and valuation are presented helps understand what is going on 'under the bonnet' but can feel intimidating. Given that how people feel about these relationships is associated with their own values, the trick is to feel more confident in making value judgements for yourself.

That is why in this chapter, there is one more example of using wellbeing data to understand culture and their role in social policy. We are going to look in greater detail and break down these processes further again. This includes a description of how the data were collected in a national-level survey. We look at the questions, as they appear in the survey, because it can be hard to imagine the mundane contexts that data originate from when you are looking at the complex results. It is also not easy to imagine what has happened already, or indeed, what happens next.

What does research do? How does it affect the world or change things? What do well-being data become when their analyses are presented as findings, and then reproduced? We will begin to think through some of these questions by following key findings, to see how they are interpreted in the real world, to imagine data's capacity to change things. We will return to the conceptual work behind what is being measured before reflecting on what the analysis is trying to do, step by step. In this chapter I want to share that it is possible to think through what quantitative analyses are doing, without necessarily doing the maths or understanding the quantitative processes and their confusing terms.

The steps involved in data analysis like the ones in this chapter are designed on the basis of how concepts go together. It is possible to understand the research on this level, even if expressing terms in an equation feels intimidating. People may be ambivalent, even outraged at understanding aspects of well-being in numeric terms, and this is also 
true of trying to describe the role of an idea of culture in delivering wellbeing aims. Yet, numbers help us understand the extent of relationships in particular conditions; they do not necessarily decide whether that relationship exists at all. You can choose to retain that judgement for yourself.

\subsection{Talking Different Languages of Value}

This chapter began its life in a Manchester hotel in 2014. I was preparing a conference presentation called 'Measuring National Well-being and Cultural Participation-why don't things quite add up?' A colleague was passing as I was editing a slide with this equation on it:

He asked me what the equation was for. I was a bit taken aback, because I had assumed that while I didn't really understand what the equation was saying, that this would be immediately obvious somehow to people who work in quantitative methods, or 'Quants'. I explained that it was from a report on measuring happiness for the cultural sector, but that I didn't think that it would mean much to many I knew. As I outlined in this book's Preface, I had experienced a general lack of data confidence in the cultural sector and I imagined that most people reading a report called 'Museums and Happiness: The Value of Participating in Museums and the Arts' would struggle to make sense of the equation. In some ways, more importantly, that this equation was probably a barrier to understanding data and these valuations more generally. My colleague joked that he wasn't sure it was talking his language either, ${ }^{4}$ and agreed it probably wouldn't make much sense to the sector.

I left the conversation with one overarching question: what does an equation like this do in this context? How does it reinforce the divide between those who see value in valuations, and those in cultural and social sectors, or people working for small charities, who maybe do not? Or perhaps, aren't sure? Could the ways that 'quants' are presented reproduce traditions called 'the Quant-Qual debate' that we touched on in Chap. 3, even outside research contexts? Is this detrimental to the ways that some people feel capable of actually reading the research reports that evidence arguments they use in their day-to-day jobs in the cultural sector? This equation triggered more questions for me and my colleague ${ }^{5}$ : Who was this algebraic expression for and what was it aiming to do? How did the 
equation relate to the headline findings, and most importantly, whose value and values might be expressed in such a way?

I wondered if we could 'follow the data' to answer some of these questions about the equation. Which we did-in our own different ways. I mostly handled the qualitative research: I looked at the report on museums and happiness, and the cultural, policy and data histories that preceded it. This work contextualised the report in various ways, enabling us to see how it 'fit' in the general overlapping concerns of data, well-being, politics and value that we have encountered throughout this book. More specifically, these include beliefs and theories about well-being and its role in society, ambitions of the movement to establish cultural value, developments in well-being metrics, which coincided with a desire for valuation from government - and questions of data's capability remaining unanswered.

'Following the data' also included 'following the findings'. In other words, understanding context also meant researching what came after the report and how its findings were used. This gave us an idea of the impact of the report, and how it was received by different audiences. Following the findings also included reproducing aspects of the original research. My colleague led on this, the quantitative side of our project. This chapter walks you through steps in the original research about museums and happiness, as well as our subsequent project to demystify what is going on in these kinds of valuations.

Earlier in this book, I covered some of the discussions about how data tend to be presented as these neutral and objective things. This means that in some cases, it should be possible to do the same thing with the same data and arrive at the same results. This is one of the reasons why there are so many 'workings' in quantitative research-including the equation we started with: this working out is presented, so it can be scrutinised, and potentially reproduced. This is also one of the reasons why quantitative approaches are often thought to be more persuasive and robust than qualitative ones. It is not necessarily that numbers are more powerful in and of themselves; rather it is assumed that less interpretation is undertaken by the researcher. Therefore, you can work towards reproducing someone's findings by following their steps in quantitative research, in a way that you would be unlikely to do in qualitative research. ${ }^{6}$

This happenstance discussion about an equation in a Manchester hotel in 2014 led us to a project that wanted to understand the value of this genre of research to the cultural sector-and beyond to charities and other areas of social policy. Were there limits to understanding and presenting the culture-well-being relationship in this way? What would happen if we 
followed the data and processes used ourselves? The headline finding of our project is that when we reproduced these processes, we had a different finding: the monetary estimates of the relationship between participation and subjective well-being do not match across our reading and the original. Why might this be?

There are a number of reasons why two pieces of research following the same steps with the same data might offer different results. We will return to this later, but first, the aim of this chapter is to 'follow the data' on a journey of informed discovery, hoping to achieve a number of other things along the way. First, break down some of the barriers between quantitative research that helps people with their advocacy, and the practitioners who will read it and need it. Second, enable people to feel more confident with quantitative expressions and some of the language and principles of quantitative research. Third, it is a reference for people to return to, and apply to other reports they need to understand, but which 'do not speak their language'. This leads me to fourth, to help people feel greater data confidence and literacy, and perhaps enable them to make better judgements for themselves about whether more than headline findings can be usefulto them or in general.

\subsection{Context: The Happy Museum and Data}

The aim is to arm museums with compelling statistics to show how a healthy culture must be at the heart of a healthy society. (Tony Butler, Director Happy Museum Project and Director Museum of East Anglian Life in Fujiwara 2013, 5)

The relationship between culture and well-being has been operationalised $^{7}$ by a number of different organisations in the cultural sector. This is particularly true in the UK. Chapters 6 and 7 have covered a number of processes and projects that want to naturalise, even celebrate, this relationship. One obvious example, by virtue of its name, is The Happy Museum (n.d-b). Established in 2011, The Happy Museum focusses on more than happiness as a hedonic ${ }^{8}$ idea; also embracing other, broader aims of the well-being agenda we covered back in Chap. 2: possibilities for sustainability, community and a sense of purpose. The Happy Museum is an advocacy organisation that has slowly grown and expanded on its activities, for example offering frameworks and training for those in the sector to understand the opportunities for the role of museums in well-being (The Happy Museum n.d-a). One of its aims was to contribute to the evidence base on the value of museums. The Happy Museum's Director, 
quoted above, invoked the values of culture and its relationship to a healthy society, whilst embracing the idea that this is best expressed with compelling statistics. This statement is testament to the will to progress towards bridging the gap between the languages of valuation and culture's values.

'Museums and Happiness: The Value of Participating in Museums and the Arts' was commissioned by The Happy Museum Project and funded by ACE. The equation I mentioned earlier originated from this report. It is important to say that the equation wasn't left floating alone to explain the workings, but the report contains details on why things were done and how. We will go through some of these explanations in the subsequent sections, elaborating for context and hopefully clarity. The key stated goal of the research was to 'look at the impacts of the arts on people's subjective wellbeing and health and attach values to these impacts' (Fujiwara $2013,7)$. The project took a 'well-being valuation approach', which we've touched on in Chaps. 2 and 7, and which I will walk you through. As I have said before, this is not a Quants textbook, and you will not read this chapter, suddenly conversant in statistics, but it should hopefully give you a better idea of what is going on.

\section{Taking Part Survey and the Data on Culture}

'Museums and Happiness' includes findings from quantitative research that used data from the Taking Part Survey (TPS; DCMS 2010). The report explains why TPS data were chosen over other surveys, based on the different variables available, sample size and so on. ${ }^{9}$ It points out that while this technique had been used before, it had not yet been used on this dataset.

We have talked about why TPS was established in Chap. 6: that it was part of an instrumental project by DCMS to address a need for evidence. Here, we are going to think about the data itself and the context in which it is generated. TPS covers England only, rather than the whole of the UK. It employs interviewers to go to people's homes, if they agree, of course, and interview them face-to-face with a questionnaire. The survey questionnaire asks about all different types of activities. A script asks the interviewer to request the interviewee to think in great detail, and to be specific, for example:

Firstly, I would like you to think about all the walking you have done. Please include any country walks, walking to and from work or the shops and any other walks you may have done. 
In the last four weeks, that is since [TODAY'S DATE MINUS FOUR WEEKS] have you done at least one continuous walk lasting at least 30 minutes? ${ }^{10}$

Were you to participate, you would be asked this, and more questions and clarifications, and finally whether your walking was 'for the purpose of health or recreation (not to get from place to place)'. The questionnaire then asks the same questions about cycling, for example; and so on. All in, you would expect to be speaking to the interviewer for about 40 minutes. In Box 8.1 you can see the museum questions from 2009-2010 survey.

\section{Box 8.1 The Museum Questions from the Taking Part Survey} 2009-2010

The museum questions ${ }^{11}$ were phrased slightly differently from those on cycling and walking and listed below:

During the last 12 months, have you attended a museum or gallery at least once?

1. Yes 2. No-1. Don't know

In the last 12 months, have you attended a museum or gallery...?

1. In your own-time 2. For paid work 3 . For academic study 4 . As part of voluntary work 5 . For some other reason - 1 . Don't know

How often in the last $\mathbf{1 2}$ months have you been to a museum or gallery [in your own-time] [or] [as part of voluntary work]?

1 . At least once a week 2 . Less often that once a week but at least once a month3. Less often than once a month but at least 3 or 4 times a year 4 . Twice in the last 12 months 5 . Once in the last 12 months - 1 . Don't know

To make everyone's answers analysable, all responses are combined into one dataset. Alongside questions on activities are questions about personal characteristics, for example, income, how many people live in your household, age, marriage status, whether you have children and so on. These variables allow researchers to understand how many different types of people 'take part' in different activities. These data also allow DCMS to see whether the percentages of different groups of people participating in different activities go up or down over time. These are reported on by DCMS in 'Statistical Releases', in which the results are synthesised and 
available for anyone to access. ${ }^{12}$ They include information on, for example, the numbers of people who have participated in the arts in the last twelve months, and the same for sport, and so on. DCMS (n.d.) also releases a number of 'Focus On' reports each year, which they call 'short stories' (DCMS 2015a, 2). For example, in $2015^{13}$ there were ten of these reports, including one on well-being (DCMS 2015b) and one on art forms (e.g. DCMS 2015a); in 2016, there was one on diversity (DCMS 2016).

\section{Box 8.2 Variables: A Reminder}

A variable takes different values in different situations. These values vary between cases or observations (which in this case are people but aren't always). They also vary over time or space.

So, for example, height varies across people, because some people are taller than others, but also within people over time, because people get taller as they grow up.

It is a variable because it varies. It is this change or variability that is measured, whether over time, or to compare characteristics.

In a regression, you would analyse the relationship between an independent variable, or independent variables, and a dependent variable.

Because we look at how variations in independent variables can predict values of a dependent variable,

- independent variables are sometimes called predictor variables,

- dependent variables are sometimes called outcome variables.

So, if you want to see the relationship between age and museum attendance, presumably, you are not expecting museum attendance to make someone age, but you might want to understand if older people are more likely to attend museums. Therefore, age would be your independent variable.

To measure the culture-well-being relationship, we need an independent variable (for culture) and if we wish to measure culture's relationship with well-being, then we need the chosen well-being 


\section{Box 8.2 (continued)}

variable to be the dependent variable. For ease, let us say because we want to see whether people who participate in culture have higher well-being.

*We also want to add other independent variables to make sure that we're not inadvertently measuring other relationships as well. For example, if married people report higher well-being on average, and are more likely to attend cultural events, we should include marital status as an additional independent variable. Without accounting for it in the analysis, marriage could be a confounding variable, meaning it could exaggerate the results. Therefore, here marriage would be controlled for, even though it is not of primary concern in the outcome.

\section{The Well-being Data Available in the Taking Part Survey}

Happiness taps in to people's emotions, technically their affective state, and hence tries to gauge people's moods at that moment. (Fujiwara 2013, 12)

As we saw in Chap. 6, part of thinking through how humans experience well-being, is acknowledging these processes are cultural and centre ideals of 'society'; they also involve imagining moments of social or cultural engagement and how they affect people on an individual level. Questions of when and how we experience particular well-being effects (or, perhaps, different kinds of well-being) are a key part of the puzzle of philosophers' thinking for centuries. As we have also seen in Chap. 4, this problem has driven recent developments in well-being measurement, arguably shaping what we have called the second wave of well-being and happiness economics. Understanding people's emotions in this way is used in various research contexts: whether using the diary reconstruction method (DRM) outlined in Chap. 4 to understand how people are doing in the day-to-day life, or to understand how a major event, such as the financial crisis of $2007 / 2008$ or COVID-19 has impacted on people's well-being at scale.

What is hopefully clear by now is that deciphering which particular moment is actually being captured when attempting to measure an 'affective state' (such as happiness), and whether that is the moment that is relevant to your research question, has proved complex for a long time. Chapter 4's Fig. 4.1 and the related section outline how approaches to 
understand this differ, yet are related. 'Museums and Happiness' uses TPS data, which now include all of the UK's Office for National Statistics' four well-being questions (ONS4), ${ }^{14}$ and has since the 2013-2014 dataset. However, the research we are looking at analysed data from 2005 to 2011 , so before this change. Therefore, the question is similar, but not identical, to the ONS4 experience measures which ask about happiness and anxiety yesterday (see Table 4.2). The TPS data we are looking at in 'Museums and Happiness' understand happiness through the following question:

"Taking all things together how happy would you say you are?" on a scale from $1-10$ where 10 is described as "extremely happy" and 1 as "extremely unhappy".

The report says (as cited at the beginning of this section) that the data from this question establish someone's mood at that moment. The report continues:

This differs to wellbeing questions that contain an evaluative judgment such as life satisfaction or eudemonic ${ }^{15}$ wellbeing. Life satisfaction is held to contain a response about one's current emotions together with an evaluation of their life overall (how it measures up to their goals for instance) and eudemonic wellbeing questions tap in to people's perceptions of whether they are living a meaningful life. (Fujiwara 2013, 12)

If you return to Fig. 4.1 while reading this, you can see how this explanation maps onto the figure and the descriptions of approaches in Sect. 4.3 that follows it on how these measures are used. Notably, the 'taking all things together' part of the question makes it a 'general happiness' question, which is sometimes approached using Cantril's 'ladder of life' (Fig. 4.2). I say this, so you can probably imagine different ways you might answer this particular question.

There is a broader consideration with using national-level survey data to understand someone's 'happiness' in any moment. We have also encountered this before in Chap. 4, discussed in the section on experience measures. The ideal way of understanding happiness as an affective state is to ask people repeatedly during a particular day, over a period of days about how they feel in the moment. In other words, you would collect a sample of their moods and ask them what they are doing at that moment (which is why it is called the experience sampling method). This method is hard to translate into a survey because it is too time-consuming-for the 
interviewer and the interviewee to repeatedly ask and answer questions. This would make it too expensive to run, and difficult for many people to be available to participate in, which would then affect your sample-or, who you are talking to, and limit understanding. As an alternative, the rationale with the ONS4 experience measures is to 'replicate' or 'proxy' ESM approaches by asking respondents for their experiences and feelings relating to a whole day (yesterday).

So, let us briefly consider what is being captured by the question: these data are collected through a national-level survey and therefore at a time and in a place that is most likely completely unrelated to a museum visit. The implications of the headlines of this report is that the 'affective state' is 'gauge[d]... at that moment', but that moment is—of course-not the moment in the museum, but when the survey interviewer is in someone's home. On top of that, the question asks you how happy you feel you are overall, so it is not directing you to consider a period of time (as the ONS4 experience measures do), let alone a specific moment. So, we are beginning to encounter some limits, but this is not necessarily abnormal, because, as we know, all measures will have their pros and cons.

You may remember the difficulties in establishing whether a concert changed someone's well-being, even when you ask them immediately afterwards (Chap. 3). When the question is presented to someone by the TPS interviewer, that person may struggle to even remember the last time they were inside a museum. In truth, that is not even asked. As the box in the previous section demonstrates, the questions are about the last 12 months in general, not specifically the length of time since someone's last visit. Also, the survey did not request that they rate their happiness whilst in the museum (or before and after), but to comment on their happiness overall. Therefore, talking about measuring happiness in this way may feel confusing, because the happiness derived from visiting a museum in-themoment is not what is captured directly in the data that are available for analysis. The title of the report implies that there is a relationship between museums and happiness, which at glance for some will undoubtedly confirm their belief or personal experience that museums make them happier, and encourage better overall well-being. This, of course, may well be true. However, we must remember that not everyone is the same, and to question what the data that are available for analysis are telling us. We must remember that it might be that-in general-people who go to museums tend to be happier than those who do not. A causal relationship may be difficult to demonstrate. 


\section{Box 8.3 Causal Inference: A Reminder}

Causal inference describes the process to identify whether there is a relationship that involves the independent variable (culture) affecting the dependent variable (well-being). It means that there is an effect in the connection under study.

When looking to identify and measure causal relationships, we analyse the relationship between the cause variable and the effect variable.

To find that cultural participation is a cause of improved wellbeing (as the phenomenon), we need to establish that the cause precedes the effect, which means eliminating other plausible alternative causes. This is difficult because you cannot test this question in the real world.

The classic example is if we found a relationship between whether people were wearing shorts and whether they were buying ice cream, it wouldn't mean that wearing shorts caused people to buy ice cream, or that buying ice cream caused people to wear shorts. There is something else affecting this relationship that needs to be found and accounted for.

\subsection{Museums and Happiness AND OTHER RELATIONSHIPS}

The research reported in 'Museums and Happiness' was actually looking for more than one relationship. The equation I cited earlier in that presentation in the Manchester hotel was one of two presented in the text. The report states:

We look at the impact on wellbeing and health of participating in and being audience to the arts and of being involved with museums and compare these impacts to other activities such as participation in sport. (Fujiwara 2013,7)

This means, that as well as the 'general happiness' question, used in the TPS questionnaire, the researchers were also able to use other general questions on health. ${ }^{16}$

They also used income. We'll come back to this. But for now, we know that there are some culture variables (participating in and being an 
Table 8.1 Participation variables modelled in 'Museums and Happiness'

$\begin{array}{ll}\text { Participation variables (the independent variables) } \\ \begin{array}{ll}\text { Museum } \\ \text { variables }\end{array} & \begin{array}{l}\text { whether participants visit museums in their free time } \\ \text { a measure of the number of hours spent in museums per year } \\ \text { the number of museum visits per year }\end{array} \\ \text { The non- } & \text { whether participants had done sport or other physical activity in the last } \\ \text { museum } & \text { four weeks } \\ \text { variables } & \text { whether participants had (in the last year) participated in each of ballet, } \\ & \begin{array}{l}\text { dance, singing, playing music, painting and drawing, photography or } \\ \text { crafts } \\ \text { whether participants had (in the last year) attended exhibitions (also } \\ \text { referred to as 'audience to arts'), opera, concerts and live music, ballet } \\ \text { and dance }\end{array}\end{array}$

Adapted from Fujiwara (2013)

audience to), some other activities, including sport. For ease, we are going to call all of these 'participation variables'. You can find these in Table 8.1. The participation variables are the independent variables (or, you might find it easier to think of them as the predictor variables). The two dependent (or outcome) variables are health and subjective well-being.

The same process was used to calculate the relationship between visiting museums and happiness and 'has done sport or physical activity in the last four weeks' and happiness. This is a fairly simple process for someone who knows what they are doing, as they can run the same model multiple times, swapping out one participation variable for another. You might then do the same thing again with the outcome variable as health, going through the process of swapping the predictor participation variables. ${ }^{17}$ The takeaway point is really, that we are going to proceed by talking about the processes involved in calculating the relationship between museums and happiness, for ease of understanding, but really there are multiple museum and non-museum 'participation' variables used to calculate different associations with health and happiness in this research.

To go about achieving the aims of this research: looking at the impact on wellbeing and health of participating in and being audience to the arts and of being involved with museums' (Fujiwara 2013, 7), a well-being valuation approach was used. ${ }^{18}$ This approach aims to estimate 'monetary values by looking at how a good or service impacts on a person's wellbeing and finding the monetary equivalent of this impact' (Fujiwara 2013, 7 ). In order for us to engage with this process of valuation, it may be 
helpful to get into a mindset in which we think of participating in an activity (let's stick with museums for ease) as a 'good' or a service. By goods here we mean the same as 'trading in goods': that is, this experience has a market value; this experience can be valued in this way. That is, people can choose to spend time or money on attending museums, as opposed to on another thing, like the cinema or rock-climbing. This is a slightly different mindset, perhaps, than the idea of culture as a social good.

You have maybe spent most of this book thinking of well-being as a social good, without thinking about a social good as having a market value. In many ways, instinctively they feel opposite, as often actions to maximise something's financial value, feel at odds with a social good (we discussed this in Chap. 2 in thinking about McDonald's and the rainforest). But theoretically, all things which are good can become 'goods'. In this mindset, culture is not just a qualitative, incommensurable (has no common measure) experience. It is not only a way of experiencing fulfilment and happiness, but people can choose to consume culture, and it is something that makes them feel satisfied. This means it has utility (because it makes them happy).

Getting into this mindset helps us 'talk the talk' of valuation and imagine how culture may be quantified (in theory). When you think about it, we all have limited time to do anything, whether that is watching Netflix, going to the gym, playing video games, blowing dandelions or going to museums. Different ways of spending time might be associated with different value, but because we don't have unlimited time, we have to prioritise. The relationship between value, museums and experiential benefit is there; it is just not always readily visible to us, or something we think about.

So, if someone wants to estimate museums' impact on well-being, then they might say that they hypothesise that attending museums has a positive association to well-being, but we know more about the ways different types of well-being have a relationship with money. The amount of research on the relationship between income and different forms of subjective well-being far exceeds that on participation and well-being. As we discovered in Chap. 4, the relationship between income and happiness (the Easterlin paradox) is even described as the very turning point in wellbeing research. So, using income enables us to

1. begin to understand the relationship between museums and happiness, and

2. express this relationship in financial terms. 
Of course, we have many prior estimates of the culture-well-beingmoney relationship to work with. This is not one undisputed value. For example, there have been thousands of studies on the relationship between income and well-being. This inevitably means that there are different approaches with different results. So, a decision has to be made by the researcher about the most suitable way to estimate the relationships they are interested in, in the specific context in which they are working. This refinement of which variables to use is standard practice, so long as the decisions made are subsequently clearly outlined and are justified and the limitations to research and the caveats to claims acknowledged and discussed.

In a valuation approach like Willingness to Pay (or another of the stated preference techniques we have previously covered in Chaps. 2 and 3), the data used are from people's responses to questions which asked them for their preferences or what they value. The questions ask people to state the value themselves for a good or service. In the simplest of terms in this example, this would be: 'how much would you be willing to pay to attend museums?' There are noted cons to asking people to attribute value themselves that are acknowledged in the report.

Page 28 of the report explains that a study in Bolton in 2005 found that people were willing to pay $£ 33$ a year for museums in Bolton. The reason this is so low, in comparison to the $£ 3200$ per year in the Museum and Happiness findings, is explained as follows. It is unlikely that people will state a high value for a currently publicly available service in case they may get asked to pay for it in the future (Fujiwara 2013, 28). This is called strategic bias. However, there is not one way that strategic bias might affect the valuation. This argument works just as well as saying that some people will overinflate their willingness to pay for a museum, knowing that the more they say it is worth, the more attractive it is to fund, and the less likely they will have to pay for it, of course. We might guess that some people would be very likely to apply a high number to their willingness to pay, by virtue of working in the cultural sector. It is not possible to be sure which way strategic bias will go in this context or indeed the motivation.

There are other issues with 'willingness to pay' and other contingent valuation methods. ${ }^{19}$ They have limits in part because of the hypothetical nature of what you are often asking people. For example, 'existence value' is worth thinking about (and is, again, noted in the report). It is hard to imagine how much something like a museum or library is worth to you, as they exist and have value just in people knowing they are there, and some people want them to be there in case they-or others-want it (called 
option value). There is also the knowledge that they will be there for future generations. This is not the same as using these services, or being prepared to pay for them. When people are threatened with the removal of museums or libraries they do not use, they see a hypothetical value in them. Or, the theory goes that there is a value in knowing they exist at all.

The TPS data used in the 'Museums and Happiness' study did not contain people's own valuations. This means that it was not possible to have 'preference satisfaction' measures in the valuation model. Instead, it used a well-being valuation approach. The report explains that this overcomes the biases in people's own evaluations by estimating for them. The 'Museums and Happiness' report states that 'two very distinct measures of wellbeing are used' in the Bolton Study on the one hand and 'Museums and Happiness' on the other (Fujiwara 2013, 28). The report continues: 'there is no philosophical or theoretical reason why values from these methods should converge in anyway [sic]' (Fujiwara 2013, 28). This means that even though these two pieces of research are both using economic approaches to value museums and well-being, the findings should not be expected to be similar. When you think back to Chap. 7 , and the importance of how culture and well-being are operationalised, versus the headline findings from reviews of evidence, you might think to yourself that this does not bode well for arguments on how much we can know the relationship between culture and well-being, if we cannot expect studies to have more similar results than $£ 33$ and $£ 3200$ as answer to the question 'what is the value of museums to people in terms of well-being?'

Let's return to the well-being valuation approach used here and how it can know the value of something to people without asking them. It requires a dataset to include a measure of well-being, a measure of the good we are interested in valuing [museums] and other determinants of (things we know are associated with) well-being, such as income. The logic is that say we imagine a unit of happiness as an 'HAP', and we know that $£ 1$ neatly equals exactly 2 HAPs (how convenient), economic approaches can use what we know about this relationship and apply it to understand others. The technique runs on the following rationale:

so, 1: if 'museums have a relationship with well-being that we need a value for'

and, 2: 'money has a relationship with well-being that we have a value for' then, 3: 'how much money makes you as happy as a given unit of museums' is essentially the question. 


\section{Box 8.4 Coefficients}

What they are estimating here are the coefficients behind particular types of participation. When you look up the meaning of 'coefficient', you are likely to see something like this: 'a numerical or constant quantity placed before and multiplying the variable in an algebraic expression'.

It's probably important to bear in mind that the amount of museum participation isn't how many times someone goes, how long they are there or how many people are inside a given museum. Museum participation is a variable in and of itself that will represent whatever people answered in response to the survey question, and/ or how those data have been coded.

The coefficient is basically: if you increase a unit in your independent variable, how large an increase do you get in your dependent variable?

In this example, the variable 'museum participation' means 'visits to a museum a certain number of times a year', so if you increase the museum participation, how much increase in the happiness variable is there?

The variable might have values between 0 and 1 (which means the unit increase is 'goes from not doing it to doing it', and it might be continuous in hours, or could be another type of proportional increase). Say it is one of the questions from TPS in Box 8.1.

During the last 12 months, have you attended a museum or gallery at least once?

1. Yes 2. No - 1. Don't know

This is either 0 or 1 , for yes or no. In this instance, if people take the don't know option, they won't be included. The coefficient is how much of the variable 'attended museum or gallery' there is. So, the coefficient behind 'goes to museums or not' might be large, but that's because it only goes from 0 to 1 .

However, if you have 'number of hours spent in a museum', with values lying between 0 and 1 , you would expect a much smaller coefficient because the max number of hours is much more than 1 . 
Remember that using income is (1) a way into understanding the relationship between museums and happiness, and (2) a way to express this relationship in financial terms.

\section{Box 8.5 Imagining Units of Happiness, Museums and Money}

Say a HAP $=1$ unit of happiness.

You went to the British Museum yesterday, and your HAPs increased by 8 .

The day before yesterday, someone gave you $£ 1$, and your HAPs increase by 2 .

This suggests that going to the British Museum is equivalent to getting $£ 4$ increase in income. Or if you were to stop going to the British Museum, but were to get $£ 4$, you would stay equally happy.

Once you have established this relationship, you can equate museum visitation happiness to happiness from getting more income. This is one way of valuing museums for their relationship to happiness.

In a previous study, the researcher found that 'when using lottery wins as an instrument for income... the size of the impact of income on happiness increases more than ten-fold' (Fujiwara 2013, 26). The reason why lottery wins are thought to be a good indicator for income is they are from outside of a person's day-to-day life. Theoretically, this makes it easier to determine the impact of the money on someone's happiness. You might find yourself asking 'well, how can you know how much of the happiness from the lottery win is from the increase in wealth, and how much of the happiness is from the joy of winning?' There is even a whole body of research that argues that winning the lottery doesn't impact on happiness at all. ${ }^{20}$ However, the rationale in 'Museums and Happiness' is that it is suitable 'to get a good estimate of the causal effect of income' (Fujiwara 2013, 26).

The report also explains prior studies 'derive implausible large value estimates for non-market goods' because of this discrepancy in income (Fujiwara 2013,26). Notably, a CASE ${ }^{21}$ study using an income compensation approach found that going to the cinema once a year had a value of $£ 9000$ per household per year (Matrix Knowledge Group 2010a, b). The report states that 
Since there is no suitable instrument for income in the Taking Part data we also estimate values using an income coefficient that has been multiplied by 8 (which is in the scale between 2 to 10 , which is the level of bias found in the studies above, but weighted more towards 10 since the analysis of happiness data using the BHPS suggests that the true impact of income on happiness may be more than ten times larger than the OLS coefficient). (Fujiwara 2013, 26)

In simplest terms, the idea is that those previous studies are able to 'instrument for income'-which means that they can isolate the benefits of money from the benefits of being a high earner. It is important to remember that as a higher earner, you are unlikely to have data collected on how long you went to the loo; maybe you have a nicer office and get to expense your coffee, perhaps even someone else goes and gets you nice coffee from your vendor of choice? In the same way it is difficult to disaggregate the joy of winning from the impact of money, it is difficult to account for all the ways that being a higher earner may improve your life outside of money alone.

Returning to these previous studies, they found the discrepancy between income and lottery wins. There is therefore a number for that that can be plugged into the valuation. The report explains that this means it is therefore plausible to use people's income, as declared in the TPS, and multiply the coefficient by 8 , based on the fact that the estimates between studies that 'instrument for income' and those that don't tend to differ by around this much in previous studies. This is accounted for in the report, like this:

This is part of the reason why Wellbeing Valuation studies that do not instrument for income derive implausible large value estimates for nonmarket goods. (Fujiwara 2013, 26)

The report accounts for the robustness of this approach, like this:

The wellbeing valuation techniques used here are in line with welfare economic theory on valuation (which underlies all cost-benefit analysis and SROI techniques), but we should note that these values should not be seen as amounts that people would actually be willing to pay per year for these activities. This would only be the case if people satisfy their preferences solely on the basis of what makes them happy, but other factors may impact on people's preferences and market decisions. These values should be seen as the equivalent amount of money required to create the same impact on 
people's happiness and they are useful as they show us the magnitude of importance of museums and the arts to people. (Fujiwara 2013,33)

In other words, these valuation principles are considered robust, but these values are not what people would actually be prepared to pay. Instead how much extra money would keep someone at their current levels of happiness if they had to stop participating. In a section called 'Key Findings', the valuations are presented as follows:

$\checkmark$ People value visiting museums at about $£ 3200$ per year.

$\checkmark$ The value of participating in the arts is about $£ 1500$ per year per person.

$\checkmark$ The value of being audience to the arts is about $£ 2000$ per year per person.

$\checkmark$ The value of participating in sports is about $£ 1500$ per year per person. (Fujiwara 2013, 8)

Using ticks for bullet points may feel an unusual way of presenting findings, especially when there are so many caveats to these estimates, particularly whether people actually do value museums like this, or not. More importantly, these statements imply that people value participation in these monetary terms. Again, it is not that people do not-either consciously, or unconsciously, but the presentation might be confusing to the report's audience. These are in fact what the report calls 'the compensating surplus' for these activities. In other words, according to these calculations, this is the amount of money people would in theory give up in order to undertake the activity. In other words, the finding is that on average, people who go to museums are as happy as people who don't go to museums but are paid $£ 3200$ a year more.

This can be difficult to understand when you are reading the key findings from a report as a non-expert, and especially difficult when they are presented out of context, like in a daily national newspaper. We will now look at how findings can appear in different contexts in ways that can be distracting.

\subsection{Following the Findings}

Even when you follow the processes involved in estimating the relationships in the 'Museums and Happiness' research, as they are broken down here, it still might be hard to see how this valuation works-from a common-sense perspective. Following the data did not find data in which 
people explicitly value visiting museums at about $£ 3200$ per year, and yet this is what it appears to say. This is confusing for people who are not familiar with these kinds of valuations.

These valuations were presented as Key Findings in bold in the introduction on page 8 . However, the Caveats section on page 33 clearly states:

The wellbeing valuation techniques used here are in line with welfare economic theory on valuation (which underlies all cost-benefit analysis and SROI techniques), but we should note that these values should not be seen as amounts that people would actually be willing to pay per year for these activities. (Emphasis in original)

The findings are partially presented in the Director's Foreword, on page 5 , which states:

By finding that the individual wellbeing value of museums is over $£ 3000$ a year, the report makes a strong case for investing in museums.

We are going to pause and follow some findings to see how and why this is important. They were reproduced partially in a number of places. The Museums Journal described the report as having 'found museums improve people's happiness and perception of good health, even after other factors that might be influencing them are accounted for' (Harris 2013). They also go further than the original report by claiming that visiting museums 'boosts' happiness. Notably, this exaggerates the claim of the report-not in the monetary estimates, but the idea of impact is exaggerated to become a boost, when impact was not being measured in these terms at all. This is an example of translating value and impact from one setting to another, and how it can easily be misinterpreted.

This is especially important because it is not a one-off. This is not the only report of this nature with key findings that were altered when they were reproduced. A report written to the DCMS in 2014 saw its findings become muddled before it reached the headlines. In Quantifying and Valuing the Wellbeing Impacts of Culture and Sport (Fujiwara et al. 2014), the authors present the key findings as:

- Arts engagement was found to be associated with higher well-being. This is valued at $£ 1084$ per person per year, or $£ 90$ per person per month. 
- A significant association was also found between frequent library use and reported well-being. Using libraries frequently was valued at $£ 1359$ per person per year for library users, or $£ 113$ per person per month.

- Sport participation was also found to be associated with higher wellbeing. This increase is valued at $£ 1127$ per person per year, or $£ 94$ per person per month.

Much like in 'Museums and Happiness', the report for DCMS also includes estimates for many activities. Towards the end of the report, on page 29, the authors express the finding that participation in dance has the highest value of $£ 1671 \mathrm{pa}$, followed by swimming ( $£ 1630 \mathrm{pa})$ and library visits $(£ 1359 \mathrm{pa})$. The finding about dance appears in this form, only twice in this report, in a regression table and as a finding underneath it in bold, around two-thirds of the way through the report. In other words, it is far from a headline finding. Despite the lack of prominence of this monetary estimate in the original report, it finds itself at the beginning of a journey which results in a national newspaper headline, like this one in the Telegraph: 'Dancing makes people as happy as a $£ 1600$ pay rise' (Swinton 2016).

This is why following the data in different ways (and in different directions: back in time and into the future) provides valuable context. In seeing where interpretations of the findings end up, we can see the impact of claims to impact. These are attractive headlines because they feel simple to grasp, and yet, as with many headlines, they obscure the real story. In recognising the appeal of these monetary headlines, we are able to see the market value of valuations like this. We can see that the numbers-and the data practices behind them-are valuable to a sector wanting to find what the Happy Museum's director calls 'compelling statistics', as the language to articulate its value to Treasury.

However, these presentations of findings also create barriers for those who will scoff at how ridiculous an idea it is that anyone could know that 'dancing makes people as happy as a $£ 1600$ pay rise'. We must also question how helpful they are to anyone in the dancing profession who might like to understand how to translate what they do into something that is valuable to a funder. At the moment, much of what is going on behind the headlines is quite obscure for those who most need to understand and articulate this relationship for themselves. This calls into question the value of these valuations in the current context. 


\subsection{How Was the Value of the Relationship Between Museums and Happiness Calculated?}

The previous sections have walked you through some of the contexts of the research in 'Museums and Happiness': the data, the concepts and the relationships being modelled-as well as an aside about how appealing headline findings are when they are formulated in monetary terms that appear easy to grasp. We have looked at what this example of quantitative research was aiming to do with a hypothesis on various relationships, but fundamentally: that museums improve people's happiness.

This one hypothesis emerges from a series of contexts: the naturalised relationship between culture and well-being and a hypothesis that this can be measured; a desire to isolate the qualities of museums in this relationship to argue their value; philosophical reasoning on how this is possible; prior research indicating other values that help understand the relationship in question - and prior research indicating methods and models that will be useful. We are now going to look at how the numbers were generated.

We discussed how the same model could be run over and over again, changing one variable each time. The calculations, when taken together, can model how when an individual goes to a museum, their happiness goes up because of the experience. This can account for some of the additional things that could be going on. One might be that their happiness could be going up directly because of the specific experience, and also indirectly, because their health could be getting better because their happiness has improved. So, again, it is not 'museums' that is valued, per se, but a series of variables which are different in each set of models, but some of these variables are about going to museums. I am reproducing Table 8.1, together with Table 8.2, so you can see the variables together.

As a reminder, the key findings are summarised as follows in 'Museums and Happiness' (Fujiwara 2013, 8):

- People value visiting museums at about $£ 3200$ per year.

- The value of participating in the arts is about $£ 1500$ per year per person.

- The value of being audience to the arts is about $£ 2000$ per year per person.

- The value of participating in sports is about $£ 1500$ per year per person. 
Table 8.2 Variables modelled in 'Museums and Happiness' that are not about participation

\section{Other variables}

\section{Binary variables for each of:}

- marital status,

- religiosity,

- educational qualifications (having General Certificates of Secondary Education

(GCSEs) and above vs not),

- sex,

- employment status,

- frequency of meeting friends (at least once a month vs less than that),

- being in London,

- satisfaction with the local area ('satisfied' and above vs less than that),

- smoking,

- ethnicity (white vs other),

- volunteering;

Scales for:

- numbers of children in the household

- and how often participants drink (from 'never' to 'every day').

- The self-rated health measure is also incorporated into the $\mathrm{x}$ vector.

Bands of:

- income in $£ 5000$ bands

There are four regression tables in the report that estimate the relationships between

- museum participation and happiness

- museum participation and health

- 'audience to arts' / arts attendance, arts participation and happiness

- 'audience to arts'/arts attendance, participation and health

Just to remind you, that all these variables in the regressions tables began their life around someone's kitchen table, or on their sofa, answering the questions of an interviewer, using the TPS script. Let's consider two questions again. We have already thought about the subjective wellbeing question. I have copied the explanations from the report as to why each variable was used in the table. It is not normal practice to display these two aspects of methodology together like this, but I find it helpful to see the what and the why (Table 8.3). 
Table 8.3 Health and subjective well-being variables, questions and rationales in 'Museums and Happiness'

\begin{tabular}{lll}
\hline Variable & Question from TPS & Rationale for the question \\
\hline $\begin{array}{l}\text { Subjective } \\
\text { well-being }\end{array}$ & $\begin{array}{l}\text { 'Taking all things together } \\
\text { how happy would you say } \\
\text { you are?' on a scale from 1 } \\
\text { to } 10 \text { where } 10 \text { is described } \\
\text { as 'extremely happy' and 1 } \\
\text { as 'extremely unhappy' } \\
\text { 'How is your health in } \\
\text { general?' on a scale from 1 }\end{array}$ & $\begin{array}{l}\text { 'Happiness taps in to people's emotions, } \\
\text { technically their affective state, and hence } \\
\text { to } 5 \text { where } 1 \text { is 'very good' (Fujiwara 2013, 12) }\end{array}$ \\
$\begin{array}{l}\text { and } 5 \text { 'very bad' } \\
\text { Health }\end{array}$ & $\begin{array}{l}\text { '...questions on general health will cover } \\
\text { menth and some aspects of well-being or happiness } \\
\text { that are not captured in the stand-alone } \\
\text { happiness question' (Fujiwara 2013, 13) }\end{array}$ \\
\hline
\end{tabular}

Adapted from Fujiwara (2013)

It is interesting that the rationale behind using health is stated as it may pick up on mental health, which may pick up on well-being and happiness. Of course, it does not necessarily follow that responses to a health question will 'pick up' on happiness and there is much work on these complex relations. For example, Clark et al. (2018) find that measures of mental health explain more variation in well-being than measures of physical health. Again, it is not that this is not going on, but it is hard to say that it definitely is.

As the reader, you can make your own decisions on whether this question 'how is your health in general?' may be likely to collect meaningful data regarding subjective well-being for respondents. You can do this by imagining how you might answer this question, and whether you feel you would respond about your general health in a way that incorporated your subjective well-being. You might also do this for others you know well, who, for example, might identify as having poor physical health, but are generally happy, and vice versa. Again, this is not to say that because people with poor physical health are susceptible to poor subjective well-being that the health question cannot pick this up.

The other thing to remember here is that this representative sample was asked these questions between the years 2005 and 2011 . When this report was written in 2013 , the general public would have made less association between health and happiness. Arguably, much advocacy and attentionraising have happened in the last few years, which would possibly change 
how people align health and subjective well-being. Back in 2005, culturally, it would have been different again. Therefore, when claims are made about how one thing picks up another, we can all think about the contexts in which the questions were asked, how we might answer them, and begin to think about the assumptions made on this basis.

Perhaps another reason that the study includes health is that it would have helped the process of comparison across the two models, in that it offers two measures of subjective well-being (according to the theory that health will pick up on subjective well-being). It will therefore be possible to check for robustness. This is because, and we should continue to bear this in mind, no measure is perfect. Having multiple measures that are shown in previous studies to be related to the relationship you want to understand will add confidence to your finding. That is, if they are all pointing in the same direction.

In summary, the research reported on in 'Museums and Happiness' compares the relationships between participation (various) and subjective well-being, and income and subjective well-being, by interpreting what the coefficients mean. In line with standard practice, assumptions about the measures of subjective well-being and everything else have been stated. So, there is a theory behind why particular variables are used, and what they can tell us (and the limits to what they cannot), and efforts have been made to communicate them. It gets confusing when the coefficient of the relationship between income and subjective well-being is then substituted with other estimates (multiplying by 8 ) that emerge from other reports which used different modelling techniques, different variables and concepts. They may also be based on other conceptualisations that may have been used in previous examples of the well-being valuation technique. The researcher also points out that this part of the process is also established, however, and has also been accepted by Treasury ${ }^{22}$ (p. 8).

Following the key findings on page 8 , some caution is advised in the report, for a number of reasons. I summarise these below (the text in brackets aims to explain the reason behind caution being required):

- arts participation and museum attendance are not randomised (without a randomised sample, claims to causation are limited)

- there are likely to be hidden factors that affect both participation and the outcome variables

(it is not possible to isolate participation from all other possible variables to be sure that the effects measured are because of participation 
in museums, rather than any of a number of other things that could affect well-being)

- it is possible that the described causal relationship could be backwards (it might be that happier people tend to go to museums, rather than museums make you happier) (Fujiwara 2013, 8).

These caveats, briefly explained, are: if you really wanted to understand the relationship between museums and happiness. In a theoretically perfect world, you would engineer a sample of people that you could then randomise, making sure that half had gone to museums and half of them not, and see whether one group's happiness is higher on average at the end than the start. This is a randomised control trial (RCT) used as the gold standard in medicine to understand the effects of medication or other interventions and has become increasingly popular in policy-making (Haynes et al. 2012). Yet, such a test is not really practical or ethical in the social sciences-making it very imperfect for a well-being researcher. As I have said before, it is important to ( 1 ) use the best available data and be clear on their limitations, and (2) imagine the origins of data. For example, imagine a reality in which people were surveyed en masse in an RCT like this. It would be unethical for the cultural sector to force half the population into a museum and forbid the other half from going in for a year in order to model its value! Also, RCTs use placebos, so people who have not been dosed don't know. It's not as if there's a placebo version of a museum you can send people to.

When it comes to the hidden (latent) factors, the explanation in the report is useful. There are always likely to be some influences that cannot be observed in the data available.

For example, extraverted people may be more likely to participate in the arts and also are more likely to report higher happiness and wellbeing, which means that any observed relationship between the arts and happiness may in part be driven by this personality trait rather than the act of participation itself. (Fujiwara 2013, 8)

Latent traits are personal characteristics that affect what people do, but which cannot be measured directly. So, for example, some people are more curious about the world than others. This would mean 'curiosity about the world' is your latent variable of interest, and maybe those people are both more interested in going to museums and are happier, but you can't just ask people 'how curious are you about the world?' to find out. 
As a result of these typical limitations, it is hard to be sure whether it is the going to museums per se that means people are happier, or whether it's some latent trait that means that people who are more likely to go to museums are more likely to be happier. As we know, one of the key issues with the evidence base on the value of culture is that most of the research struggles to argue that 'doing culture makes you well-er', rather than people who are more well participate in culture.

These caveats are all threats to causal inference. Yet, as the report points out, this 'level of rigour... is anyway normally acceptable in public policymaking and policy evaluation in OECD governments' (Fujiwara 2013, 8). Therefore, the report implies that there are a number of limits to the claims that can be made, but that these limits are considered acceptable. In other words, there is a shared understanding that this is acceptable between experts who do valuations and experts in government who accept them as evidence.

\section{Some Reasons Why Findings May Differ}

As I mentioned in Sect. 8.2, we began a journey which involved understanding the contexts in which the research in 'Museums and Happiness' was undertaken. My colleague also looked at the quantitative work and used the same data, following the methodology section, to try and reproduce the results. The headline finding of the quantitative work in our project is that the monetary estimates of the relationship between participation and subjective well-being do not match across the two pieces of research. There are a number of reasons why this may be the case.

Why the difference? The second study may have recoded variables in different ways from the initial study. As we know from Chap. 3, coding ordinarily requires human decision-making on what to code how, and there is no single objectively correct way to code variables-all approaches have their own pros and cons under different circumstances. However, what follows from that is that the difference in coding, based on the way it is reported, leads to the finding being backwards. By this, I mean that there is a positive relationship between participation and happiness, but not between attendance and happiness. For example, people who play a musical instrument are happier, but people who go to concerts aren't. In short, the reports' key headlines, and their focus on the positive relationship between happiness and attending particular activities, were not the same when reproduced. 
There are also questions about how 'participation' and 'audience' were operationalised in the analysis. The 'Museums and Happiness' report includes some variables and excludes others in its construction of these terms. This is another example of how models require decisions, and it is difficult to be certain that such decisions are not affected by bias, particularly regarding which variables relate to happiness and which do not. We discovered in Chap. 7 a number of ways that the operationalisation of culture and well-being is important. If the operationalisations are too narrow, and 'participation' and 'attendance' do not include all activities that we might want to be classified within these scales, then the apparent positive effects from participation could reflect something broader than just the publicly subsidised cultural sector. It may be that the positive associations of participation in publicly funded culture are similar to those of playing in a darts team or watching Eurovision with friends.

Alternatively, if the operationalisations are too broad, then the positive association between participation and happiness might be driven by one activity, or type of activity, and other activities are then undeservedly classified as being associated with happiness. For example, if dancing is associated with happiness but playing a musical instrument is not, and these two activities, along with several more, are combined into a single variable for whether or not people have participated in the arts, then dancing will be under-credited for its association with happiness, while playing an instrument over-credited. We encountered something similar in Chap. 7, where the incorporation of 'social activity' in the category called 'cultural access' with multiple other variables made it difficult to establish what the effect of cultural participation might be. We also encountered this in Box 7.6 with the hypothetical situation that young people don't like jazz music, but older people do, if you looked at everyone together you would likely find that the two groups would cancel each other out, to a degree, finding that people weren't really bothered by jazz at all.

Most importantly for the context of this book and chapter, data are not neutral, data modelling requires many human interventions, such as cleaning and coding, and experimenting with different ways to derive a relationship from the data. This leaves the processes open to human error, numerous biases and disagreements in a way that is not ordinarily accounted for. The claims made may not reflect the data collected, given the questions asked, and through careful reading we do not need to necessarily be quantitative social scientists to ask questions about where headline findings came from. 


\subsection{Conclusion: The Value of Valuation}

Value is, in other words, both various and variable. (Throsby 2001, 28)

Where are we with our thinking on the value of valuation? If some people in the sector work in the sector because they know it improves happiness from their own experience, do they need proof that this is true? Even if this validation comes from research that is not immediately legible to them, is it necessary to understand the findings cited in detail? How important are the various contexts of this research and the potential limitations of its findings for those who want to use it? The Museums Journal described the report as having 'found museums improve people's happiness and perception of good health, even after other factors that might be influencing them are accounted for' (Harris 2013), and goes further than the original report by claiming that visiting museums 'boosts' happiness, as opposed to museum-goers being happier. While the research project aimed to contribute to the evidence base on the value of museums, its findings are extended by those who wish to see such positive results. How does this impact positively or negatively on the status of evidence in this area-and the arguments for the value of culture?

Previous chapters have explained why there is an avalanche of numbers, and the various stories of why quantitative approaches to understanding well-being tend to dominate research used in policy. Population-level understandings of well-being are necessary to understand geographic, racial and gendered disparities. Revealed discrepancies can then indicate where policy investment should focus (in theory, although these analyses were not included in the 'Museums and Happiness' research). But we must scrutinise the relationships involved in these processes - theoretically and empirically. To do this requires more people feeling like they could understand well-being data. This takes practice and familiarity, but most importantly, more care is needed in research and data communications to move towards more shared understandings.

This book aims to help people feel more comfortable with data by explaining what is going on. This chapter has offered snippets of a step-bystep consideration of the data contexts: their origins, how the data were used, how researchers arrived at these results, and how these findings were then used by others. We looked at all the decisions made, and how reproducing methods with the same data does not always lead to the same results. We also considered how claims were made, and findings subsequently 
shared. More care is required around transparency around research: even when reports are transparent, more effort could be put into doing transparency differently, to improve understanding and enable people to use research more fully. While these valuations may work for HM Treasury, there are multiple audiences for research like this, and those who present it, could try harder to speak different languages and be more understandable.

At the moment, this sort of research is not published in a way that makes it accessible. Instead, the culture of this kind of research more broadly tends to mean that only headline findings are accessible to cultural and social policy practitioners, who are reliant on data and expressions of data for advocacy, yet are not necessarily comfortable with their origins. Stating one thing in headline findings, but explaining how the meaning is slightly different in practice in bits and pieces further into the report is not necessarily making it as understandable as it could be, and yet it is the norm. The Happy Museum aspired to produce compelling statistics to bridge the gap of cultural values and valuations, and the research behind the report aimed to meet this challenge. However, the research met the aims of valuation, rather than the needs of those who need the research. Acknowledging this demands resource and skill in and of itself, but the culture of research for policy and social policy organisations could change to make the ways in which it uses data and discusses limitations and caveats more easily understandable.

This chapter presented one example in great detail to be a reference point for readers to come back to, to aid future understandings of how well-being data can be used. As this book has acknowledged elsewhere, there are still many issues in data and evidence that are relied on for cultural and social policy. In the age of well-being measures and measurers, it is important that we all feel able try and engage with the data and the claims on our terms-should we wish to. Given that how people feel about these relationships is imbued with their own values, the key is to feel more confident to ask questions and make value judgements for yourself.

\section{Notes}

1. Quality adjusted life years (QALYs) are explained in Box 2.5, in Chap. 2.

2. The two valuation techniques are evaluated for their possible use in culture in O'Brien (2010) Measuring the Value of Culture: A Report to the Department for Culture Media and Sport. The Arts Council Strategy, 
Achieving Great Art for Everyone (2010), includes a number of artists on the value of the arts, including Jeremy Deller and Tim Etchells, who are cited here.

3. If you are reading this chapter a while after reading previous ones, then the cultural sector is a broad description of cultural institutions like libraries, heritage sites, museums, theatres and so on. Crucially, it is not only about the buildings themselves, but all the ways people make and consume culture and can include Netflix and outdoor festivals.

4. I have since learnt that actually there are differences in the ways that different disciplines express characters in equations; and so, arguably they also talk different languages in this way, but we don't need to get into marginal differences between economists and statisticians here.

5. It is really hard speaking for him. If truth be told, I am not sure I knew what he was thinking, exactly, five years ago.

6. Many qualitative researchers argue that the value of context, bias and subjectivity is too important to qualitative research to enable it to be reproduced in a way that findings could be repeated.

7. In quantitative research, operationalisation refers to the process through which abstract concepts, such as happiness, are translated into measurable variables. This is different from the way we use the word in day-to-day discussion. When we operationalise something, we more generally and simply put it to use. See Box 7.1 in Chap. 7 for more detail.

8. Chapters 2 and 4 are good to refer to if you need a reminder on what hedonic means.

9. If you are interested in more information on the differences across BHPS, TPS and Understanding Society at the time, and why they mattered, or indeed, want to see another example of how research like this makes decisions, do look at the original report.

10. All the questions outlined, where specifically worded, can be found in UK Data Service (2009). You can find questionnaires for each year here: https://www.gov.uk/government/publications/adult-questionnairetaking-part-survey-2009-to-2010. It is worth being aware that TPS has a longitudinal element, which is an adapted questionnaire, as it wants to accommodate change. Therefore, the adapted questionnaire wants to also know 'why the change?' For example, 'you say you have participated more or less in this than last year. Why do you think that is?'

11. The formatting of the questions does change slightly over time, as adaptations and improvements are made. Again this is from the 2009-2010 schedule, available at: https://www.gov.uk/government/publications/ adult-questionnaire-taking-part-survey-2009-to-2010.

12. The statistical release page is currently in DCMS (2013).

13. Focus on reports from 2015 can be found in DCMS (2015b). 
14. Table 4.3 shows a selection of the surveys that the ONS4 have been added to.

15. This book uses the alternative spelling of 'eudaimonic'.

16. TPS also now asks more specific, subjective questions about whether people put an increase in activities down to improved or worsened health. This question is only in the longitudinal version of the survey which has been going on since 2012. It has small differences to the version of the survey used in 'Museums and Happiness'.

17. Perhaps confusingly, the calculation is slightly different for health in 'Museums and Happiness' (it does not include income), but you could swap the outcome variables in principle.

18. The report tells us that a similar approach was used in the CASE (Culture and Sport Evidence) programme (DCMS 2010), but with different data. The CASE programme used the BHPS study to value: sport, going to the cinema and going to concerts (as the variables available). It also used data from life satisfaction questions to measure well-being, rather than 'happiness' as with our case study here.

19. A really clear discussion of the limits of contingent valuation methods can be found in Throsby (2001, Chapter 5).

20. The first and most famous of these studies is Brickman et al. (1978). However, as with other previous examples of wealth and happiness, the evidence is not universal.

21. For more information on the Culture and Sport Evidence (CASE) programme, see Chap. 6.

22. HM Treasury is the government's economic and finance ministry, maintaining control over public spending, setting the direction of the UK's economic policy and working to achieve strong and sustainable economic growth. https://www.gov.uk/government/organisations/ hm-treasury.

\section{REFERENCES}

ACE. 2010. Achieving Great Art for Everyone: A Strategic Framework for the Arts. London: Arts Council England. https://collective-encounters.org.uk/wpcontent/uploads/2019/10/Achieving_great_art_for_everyone.pdf. Accessed 31 March 2021.

Belfiore, E. 2002. Art as a Means of Alleviating Social Exclusion: Does It Really Work? A Critique of Instrumental Cultural Policies and Social Impact Studies in the UK. International Journal of Cultural Policy 8 (1): 91-106. https:// doi.org/10.1080/102866302900324658.

Brickman, P., D. Coates, and R. Janoff-Bulman. 1978. Lottery Winners and Accident Victims: Is Happiness Relative? Journal of Personality and Social 
Psychology 36 (8): 917-927. https://doi.org/10.1037//0022-3514.36. 8.917.

Clark, A.E., et al. 2018. The Origins of Happiness: The Science of Well-Being over the Life Course. Princeton University Press. https://press.princeton.edu/books/ hardcover/9780691177892/the-origins-of-happiness.

DCMS. 2010. Taking Part: The National Survey of Culture, Leisure and Sport, 2008-2009; Adult and Child Data [Data Collection]. UK Data Service. https://core.ac.uk/display/74280823. Accessed 28 April 2021.

- 2013. Taking Part: Statistical Releases. Department for Digital, Culture, Media \& Sport. https://www.gov.uk/government/collections/sat\%2D\%2D2. Accessed 31 March 2021.

- 2015a. Taking Part 2014/15, Focus on: Art Forms. London: Department for Culture, Media and Sport. https://assets.publishing.service.gov.uk/government/uploads/system/uploads/attachment_data/file/802735/Y10_Art_ forms_-_FINAL.pdf.

_ n.d. Taking Part 2014/15: "Focus On...” Reports. Department for Digital, Culture, Media \& Sport. https://www.gov.uk/government/statistics/takingpart-201415-focus-on-reports. Accessed 31 March 2021.

. 2015b. Taking Part 2014/15, Focus on: Wellbeing. London: Department for Culture, Media and Sport. https://assets.publishing.service.gov.uk/government/uploads/system/uploads/attachment_data/file/476510/Taking_ Part_201415_Focus_on_Wellbeing.pdf. Accessed 31 March 2021.

_ 2016. Taking Part focus on: Diversity. London: Department for Culture, Media and Sport. https://assets.publishing.service.gov.uk/government/ uploads/system/uploads/attachment_data/file/593993/Focus_on_diversity_final.pdf.

Fujiwara, D. 2013. Museums and Happiness: The Value of Participating in Museums and the Arts. United Kingdom: The Happy Museum; Museum of East Anglian Life; Arts Council England. https://happymuseumproject.org/wp-content/ uploads /2013/04/Museums_and_happiness_DFujiwara_April2013.pdf. Accessed 29 March 2021.

Fujiwara, D., L. Kudrna, and P. Dolan. 2014. Quantifying the Social Impacts of Culture and Sport. Department for Culture, Media and Sport. https://assets. publishing.service.gov.uk/government/uploads/system/uploads/attachment_data/file/304896/Quantifying_the_Social_Impacts_of_Culture_and_ Sport.pdf.

Gilmore, A., H. Glow, and K. Johanson. 2017. Accounting for Quality: Arts Evaluation, Public Value and the Case of "Culture Counts". Cultural Trends 26 (4): 282-294. https://doi.org/10.1080/09548963.2017.1382761. 
Harris, G. 2013. Report Finds Visiting Museums Boosts Happiness. Museums Association. https://www.museumsassociation.org/museums-journal/ news $/ 2013 / 04 / 18042013$-economist-report-finds-museums-boosthappiness/. Accessed 31 March 2021.

Haynes, L., et al. 2012. Test, Learn, Adapt: Developing Public Policy with Randomised Controlled Trials. SSRN Scholarly Paper ID 2131581. Rochester, NY: Social Science Research Network. https://doi.org/10.2139/ ssrn.2131581.

Hill, L. 2017. "Only a Fool or a Knave” Trusts Quality Metrics, Say Academics. ArtsProfessional. https://www.artsprofessional.co.uk/news/only-fool-orknave-trusts-quality-metrics-say-academics. Accessed 31 March 2021.

Matrix Knowledge Group. 2010a. Understanding the Drivers, Impact and Value of Engagement in Culture and Sport: Technical Report for the Systematic Review and Database. London: Department for Culture, Media and Sport. https:// assets.publishing.service.gov.uk/government/uploads/system/uploads/ attachment_data/file/88448/CASE-systematic-review-technical-reportJuly10.pdf.

. 2010b. Understanding the Value of Engagement in Culture and Sport: Technical Report. London: Department for Culture, Media and Sport. https:// assets.publishing.service.gov.uk/government/uploads/system/uploads/ attachment_data/file/88450/CASE-Value-technical-report-July10.pdf.

Merli, P. 2002. Evaluating the Social Impact of Participation in Arts Activities. International Journal of Cultural Policy 8 (1): 107-118. https://doi. org/10.1080/10286630290032477.

Meyrick, J., and T. Barnett. 2017. Culture Without "World": Australian Cultural Policy in the Age of Stupid. Cultural Trends 26 (2): 107-124. https://doi. org/10.1080/09548963.2017.1323840.

- 2021. From Public Good to Public Value: Arts and Culture in a Time of Crisis. Cultural Trends 30 (1): 75-90. https://doi.org/10.1080/0954896 3.2020.1844542.

Nissel, M. 1983. Facts About the Arts: A Summary of Available Statistics. London: Policy Studies Institute.

O'Brien, D. 2010. Measuring the Value of Culture: A Report to the Department for Culture Media and Sport. DCMS.

Oman, S. 2013. A True Snapshot of Life? ArtsProfessional. https://www.artsprofessional.co.uk/magazine/261/article/true-snapshot-life. Accessed 31 March 2021.

Oman, S., and M. Taylor. 2018. Subjective Well-Being in Cultural Advocacy: A Politics of Research Between the Market and the Academy. Journal of 
Cultural Economy 11 (3): 225-243. https://doi.org/10.1080/17530350. 2018.1435422.

Phiddian, R., et al. 2017. Counting Culture to Death: An Australian Perspective on Culture Counts and Quality Metrics. Cultural Trends 26 (2): 174-180. https://doi.org/10.1080/09548963.2017.1324014.

Selwood, S. 2002. Measuring Culture. Spiked. https://www.spiked-online. com/2002/12/30/measuring-culture/. Accessed 30 March 2021.

The Happy Museum. n.d-a. About - Happy Museum Project. The Happy Museum. http://happymuseumproject.org/about/. Accessed 2 May 2021.

- n.d.-b. The Happy Museum Project. The Happy Museum. https://happymuseumproject.org/. Accessed 2 May 2021.

Throsby, D. 2001. Economics and Culture. Cambridge: Cambridge University Press.

UK Data Service. 2009. Taking Part: England's Survey of Leisure, Culture and Sport 2008-09: Adult Questionnaire. UK Data Service. https://doc.ukdataservice.ac.uk/doc/6530/mrdoc/pdf/6530tpyr4_adult_questionnaire_200809.pdf. Accessed 31 March 2021.

Open Access This chapter is licensed under the terms of the Creative Commons Attribution 4.0 International License (http://creativecommons.org/licenses/ by $/ 4.0 /$ ), which permits use, sharing, adaptation, distribution and reproduction in any medium or format, as long as you give appropriate credit to the original author(s) and the source, provide a link to the Creative Commons licence and indicate if changes were made.

The images or other third party material in this chapter are included in the chapter's Creative Commons licence, unless indicated otherwise in a credit line to the material. If material is not included in the chapter's Creative Commons licence and your intended use is not permitted by statutory regulation or exceeds the permitted use, you will need to obtain permission directly from the copyright holder.

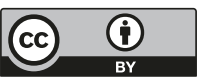

